\title{
The Present Situation and Practical Reflection of the Teaching Supervision Work in Colleges and Universities
}

\author{
Lin Jiang ${ }^{1, a}$, Hongyan Shi ${ }^{2, b,{ }^{*}}$, Man Liu ${ }^{3, c}$ and Ying Liu ${ }^{4, d}$ \\ ${ }^{1,2,4}$ Aerial Ammunition Department,Air Force Logistics College,P.R.China,210000 \\ ${ }^{3}$ Department of Basic Education, Air Force Logistics College, P.R China,210000
}

Email: Shy7823@163.com

\begin{abstract}
Keywords:Teaching supervision in colleges and universities, Working status.
Abstract. The teaching supervision system is a kind of teaching quality monitoring system used widely in Chinese universities, has played a positive role in improving teaching quality.But the current of teaching supervision in colleges and universities management system and management system is still imperfect, supervisory teams do not have a high level of specialization, works on heavy "doc" light "guide", the operation mechanism is still not clear.Therefore, the teaching supervision in colleges and universities need to strengthen the system construction, improve the supervision team specialization level, build "to supervise pay equal attention to, give priority to in order to guide" supervision mode and the scientific and efficient teaching supervision mechanism.
\end{abstract}

\section{Introduction}

Practice reflection of guiding teaching supervision and assessment, supervision and management of important functions, is an effective mechanism for teaching management in colleges and universities and powerful means, is an indispensable part of the modern teaching management system.Teaching supervision still exist some problems in colleges and universities, colleges and universities teaching supervision as an important system of college teaching evaluation and monitoring, its function and role are not fully effective play, teaching supervision work in colleges and universities is still can not adapt to the reform of college teaching situation and requirements, to strengthen the construction of the teaching supervision system, perfect the teaching supervision mechanism, improve the effectiveness of teaching supervision, will be the direction of the teaching supervision work in the future.

\section{The main problems of the current teaching supervision in colleges and universities}

The imperfect management system and management system, the role of teaching supervision is difficult to give full play to.Look from the management system, at present our country has not unified provisions on the teaching supervision in colleges and universities, universities national system of education supervision work for reference, combining with their own actual conditions, established the system of teaching supervision, the specification, but the universal existence of teaching supervision system is absent or imperfect, causes the teaching supervision responsibility, right and well-defined, many schools and even some of the teaching supervision personnel exists in the understanding of the nature of the teaching supervision work deviation, often confuse these two concepts, the teaching supervision and education supervision in the process of supervision, the different teaching supervision pattern in colleges and universities.These are affected the normal role in the teaching supervision.

The teaching supervision team specialized level is not high, the lack of scientific supervision process.At present, the colleges and universities teaching supervision team roughly divided into the following three conditions: one is all made up of retired professors or experts;One is by working part of the party and government, and on-the-job or already retired professors and experts; The third one is composed of in-service cadres, mainly is the head of the school teaching management cadres and college teaching associate dean.Three supervision teams each have advantages and disadvantages, but overall, the largest is insufficient supervision personnel knowledge structure is imperfect, teams 
do not have a high level of specialization.The old teacher in the education teaching concept and the way of supervision and young teachers there exist certain differences.At the same time, in the process of the construction of the teaching supervision in colleges and universities, there are two kinds of situations it is worth noting: one kind is belong to the "pure academic" teaching supervision personnel, their discipline professional attainments, deep knowledge, but less education scientific research consciousness, is not interested in teaching theory, the lack of necessary knowledge of education science is engaged in the teaching supervision.

On the way to weight "superintend" light "guide", is not conducive to the teachers' professional growth and professional development.On the way of working methods, teaching supervision in colleges and universities generally have "superintend" light "guide", insufficient supervision work simple.Only location to supervise the teaching supervision work, in the practical work of teachers only pay attention to find the problems existing in the teaching, does not pay attention to these practical problems to solve.Especially for the problems found in teaching supervision, no cause enough attention, also does not have to take active and feasible measures to remedy, to the teachers' teaching existing problems of the lack of effective guidance, is not conducive to the teacher's professional development;Teaching supervision at the same time, how to evaluate the teaching administrators and teachers' teaching attitude, teaching level, teaching effect, should have a scientific and reasonable evaluation standard.But now many of the universities are not such a clear standard, teaching supervision exist subjective tendency, supervision and evaluation of teaching quality to meet the real objective and scientific, or simply by listening to a few times, will assess the level of teachers' classroom teaching quality, to a great extent, weaken the authority of the supervision work.It'll be easier to make teachers to supervise the work attitude not cooperation or conflict, resulting in the contradiction between the supervisor and supervisor, antagonism, not conducive to the professional development of teachers.

The teaching supervision work mechanism, supervision work to be deepening.Currently, the operation mechanism of teaching supervision in colleges and universities there are some unreasonable place, main show is: (1) the teaching supervision lack of an independent, and can deal with good relations with various functions of the teaching, the teaching work smoothly work plan, most of the teaching supervision work to stay at the class level;(2) the teaching supervision work method performance oriented "doc" light "guide", part of the university teaching supervision work positioning only to supervise teaching check, only pay attention to find problems in the practical work, do not take the positive guidance and guidance;(3) the supervision work scope narrow, most of the teaching supervision work only stay in the classroom teaching as the center of the work scope, only attaches great importance to the supervision of teaching order, ignore the teaching files (such as the professional teaching plan and teaching outline, the talent training scheme, etc.) and related teaching links (such as experimental teaching, professional practice, students' learning situation, etc.) of supervision;(4) to supervise staff rationalization proposals do not get good implementation, the relevant functional departments and a lack of will take forcible measures to improve the teaching unit and deal with problems of teaching management ways and measures of how to improve in the process of supervision to supervise staff own quality and the lack of the level of supervision measures.

\section{The practice of the teaching supervision work in colleges and universities}

\subsection{To establish and perfect the system of teaching supervision work, strengthen the function of teaching.}

Supervision.To make the teaching supervision in administration of quality supervision, information feedback and play its proper role in decision-making consultation, need to establish and improve the relevant system, teaching supervision work clearly positioning, establishing teaching supervision work of the organization system, determine the responsibilities of teaching supervision team, experts put forward the teaching supervision work requirements, improve the method of teaching expert 
teams to work.Teaching supervision system including basic system (the task of teaching supervision, objectives, principles, etc.), the working system of the teaching supervision work of the basic procedures and responsibility system, the responsibility of the teaching supervision institutions, the duties of a supervisor and evaluation, etc.).At present, establishing and perfecting the system of teaching supervision, the ministry of education should introduce the teaching supervision regulations, in order to improve the supervision on the position and role of the teaching quality monitoring system, in colleges and universities teaching supervision major principles on the issue of clear direction.Universities should formulate teaching supervision implementation rules according to oneself circumstance, clear the responsibility of the supervisor, the rights and obligations, adhere to the "doc" "guide", guide the teachers' professional development and professional growth.

\subsection{To establish a good quality, reasonable structure of supervision team.Determining the nature of teaching.}

Supervision work in colleges and universities to the high standards of quality of supervision personnel requirements:

(1) has the rich teaching and teaching management experience, has a broad knowledge base, to help teachers improve teaching level and make the teacher get effective guidance.At the same time, the diversification of subjects objectively requires when picking supervisor should pay attention to the universality of knowledge.

(2) have higher credibility, strong interpersonal communication skills.The implementation of the supervision results need supervisor through communication between teachers and leaders of departments to implement, supervisor if communication ability is not strong, credibility is not high, to supervise the result of the implementation will be discount or not enforced.

(3) keep on learning and improving, pioneering and innovative spirit.And the rapid development of modern higher education, new theory, new ideas emerge, asked supervisor to keep on learning, understanding the forefront of related discipline development dynamic, insist on advancing with The Times, have the courage to blaze new trails, to work better.

(4) love the supervision work, care about the teaching reform, be familiar with the policies and regulations.Supervisor should strengthen the attention to teaching reform, grasp the direction of education development, familiar with relevant policies and regulations, so in the supervision work will be able to seize the center, not deviating from the direction.Tell from the team structure, the characteristics of the teaching supervision work in colleges and universities determines the particularity of teaching supervision team structure.

\subsection{The construction of a scientific and efficient teaching supervision RTOP operation mechanism.}

Straighten out all aspects of the relationship, establish a flexible operation, scientific and effective teaching supervision mechanism, is the premise of fast, efficient teaching supervision work.

(1) to establish a standard system of teaching supervision.Teaching supervision should have a comprehensive system of scientific and standard system, so that the teaching administrators and teachers' teaching attitude, teaching level and teaching effect to make objective and fair evaluation, safeguard the authority of teaching supervision, scientific, thus promotes the teaching supervision work smoothly, standardized, orderly and efficient.

(2) the dredge information feedback mechanism.Information is a basic task of the teaching supervision work, if not addressed, the supervision work will be transaction, and will not be able to play its proper role very well.

(3) set up two level supervision system.Structure tend diversification of subjects, school scale expands increasingly, and the number of the schools supervisor is limited, from the school level, the frequency of the teaching supervision and targeted cannot completely meet the practical requirement of the school each department, the supervisor can't proficient in different subjects, and it isn't 
necessary, therefore, on the basis of school supervision, to establish a secondary schools teaching supervision organization, the school teams should be "to overseers, and secondly to guide", the department supervisor, "in order to guide, and secondly to do", the two complement each other, each have focus.

(4) on classroom teaching supervision, perfect the content of teaching supervision.Classroom teaching can reflect all aspects of the school teaching management, focus on the classroom teaching, can examine of all aspects of school management.

\subsection{Paying equal attention to, giving priority to guide "supervision" of supervision mode.}

Of teaching supervision in colleges and universities is relatively pays attention to is found that the teaching problems, and not enough on how to solve these problems seriously, its handling, can not effectively promote the professional development of teachers. The facing problems and difficulties in the process of teacher's teaching not well solved, such as teaching method improvement, the application of the new teaching method and technology, the combination of teaching and scientific research, etc.Supervisor should renew the idea, the transformation of the mode of supervision work, the shift from inspection type steering to the service type to supervise, enhance service awareness, to help teachers know their own strengths and weaknesses, help them to seek the method to solve the problem. Estimator is going to do a comprehensive understanding of teacher's past, present, according to the teacher in the past and reality performance, the basis of planning the future development goals. Estimators and teacher collective negotiation formulate development goals, and create conditions, to promote teachers' efforts to achieve development goals.Aiming at the common problems in teaching supervision, targeted to carry out the training for teachers, the teaching supervision and combine the teacher training, targeted analysis and discussion of common problems in the teaching process teachers, help to shift teachers' education teaching idea and teaching mode, to improve and improve the quality of teaching.

\section{References}

[1] Huang GuiCheng.Problems and countermeasures existing in the current university teaching supervision work [J]. Journal of Medicine and School Education,2007， (9) .

[2] Ningbo university teaching steering committee. Practice and understanding of the university teaching supervision [J]. Journal of NingBo university (education science edition),2002, (6).

[3] JIA YING university teaching teams. Some theoretical thinking about teaching supervision work in colleges and universities [J]. Journal of JIA YING University,2001，（1） .

[4] Liu Rao. Developing teacher evaluation theory and model [J]. Journal of Teaching Theory and Practice,2001, (12).

[5] JU Shan,WANG CunXin. reviewing and prospecting of supervision work [J]. Journal of Development and Evaluation of Higher Education ,2008, (3). 